\title{
Health-related quality of life in children with congenital adrenal hyperplasia
}

\author{
Alyssa Halper ${ }^{1}$, Mary C. Hooke², Maria Teresa Gonzalez-Bolanos ${ }^{1}$, Nancy Vanderburg ${ }^{4}$, Thang N. Tran³ \\ Jane Torkelson ${ }^{1}$ and Kyriakie Sarafoglou ${ }^{1 *}$
}

\begin{abstract}
Background: Children with congenital adrenal hyperplasia (CAH) require life-long glucocorticoid replacement and have daily intermittent hyper/hypocortisolemia and hyperandrogenemia. Health-related quality of life (HRQL) is important for understanding the impact the disease and therapy have on physical, mental, emotional, and social functioning. Little is known about HRQL in CAH. We compared HRQL in children with CAH to healthy norms and examined how these scores related to physiologic variables.
\end{abstract}

Methods: A cross-sectional study examined 45 patients (mean age 8.2(4.5) years). Thirty-two self-reported their quality of life (QoL) on the PedsQL ${ }^{\text {TM }}$ Generic Core Scale and PedsQL ${ }^{\text {TM }}$ Fatigue Scale, and 44 parents completed a parent report. Bone age Z-scores were calculated from the most recent bone age.

Results: Children with CAH did not report lower QoL than healthy norms. However, their parents reported lower overall QoL and fatigue scores than parents of healthy norms. Children with CAH rated sleep poorer than their parents. QoL scores did not differ by sex or CAH subtype and were not associated with total daily hydrocortisone dose. Bone age Z-scores were negatively associated with child-reported emotional health and cognitive fatigue.

Conclusions: Parents of children with CAH reported a negative impact of disease on their children's QoL, but their children did not. The negative associations between bone age Z-scores and emotional health and cognitive fatigue suggest an impact from chronic hypocortisolemia and hyperandrogenemia.

Keywords: Congenital adrenal hyperplasia, Quality of life, Pediatrics, Glucocorticoids, Hydrocortisone, Fatigue, Cortisol, Androgen

\section{Background}

Congenital adrenal hyperplasia $(\mathrm{CAH})$ due to $21 \alpha-$ hydroxylase deficiency is a form of adrenal insufficiency characterized by impaired cortisol synthesis and excessive adrenal androgen production. Depending on the severity, $\mathrm{CAH}$ is classified as either classic (severe phenotype) or non-classic (mild phenotype). The classic phenotype is subdivided into simple-virilizing and saltwasting based on whether there is an adequate or deficient aldosterone production. Treatment for $\mathrm{CAH}$ involves life-long glucocorticoid replacement. In growing children, hydrocortisone is the recommended glucocorticoid at $10-15 \mathrm{mg} / \mathrm{m}^{2} /$ day [1]. Due to the short half-

\footnotetext{
* Correspondence: saraf010@umn.edu

${ }^{1}$ University of Minnesota Masonic Children's Hospital, 2450 Riverside Ave. East Bldg, Rm MB671, Minneapolis, MN 55454, USA

Full list of author information is available at the end of the article
}

life of hydrocortisone and variable inter-individual glucocorticoid receptor sensitivity, children with $\mathrm{CAH}$ are exposed to daily non-physiologic, non-circadian cortisol profiles with intermittent hyper/hypocortisolemia and hyperandrogenemia throughout each day [2]. Fluctuating cortisol and adrenal androgen concentrations may impact quality of life (QoL) and may affect energy levels in children with $\mathrm{CAH}$. There have only been two studies that have examined overall QoL in children with CAH [3, 4], and none have examined fatigue. In addition, no studies have correlated fatigue and overall QoL with hydrocortisone dosing or measures of androgen exposure and disease control in children, such as bone age Z-scores.

The aims of this study were to compare health-related quality of life (HRQL) in children with CAH treated with hydrocortisone and their parents with healthy norms, and to examine the relationship between these scores 
and physiologic variables. We report scores from both the validated PedsQL ${ }^{\mathrm{ma}}$ Generic Core Scale and the PedsQL ${ }^{\mathrm{Tm}}$ Fatigue Scale.

\section{Methods}

\section{Participants}

Children with $\mathrm{CAH}$ and their parents completed the PedsQL ${ }^{\mathrm{Tu}}$ measurements during their routine clinic visit at the University of Minnesota Masonic Children's Hospital Multidisciplinary CAH Clinic before consultation and without the investigator present. Participants included 45 children (25 females, 20 males) diagnosed with CAH (25 salt-wasting, 13 simple-virilizing, and 7 non-classic) with a mean age of 8.22 years (2-19 years) [Table 1]. Diagnosis of $\mathrm{CAH}$ was confirmed by biochemical and molecular testing. Children between 5 and 19 years of age $(n=32)$ completed the self-report measures, and parents of children between 2 and 19 years of age $(n=44)$ rated their child's HRQL on a parent proxy-report form. The University of Minnesota Institutional Review Board approved the study, and informed consents from all participants and assents for children older than 7 years were obtained.

\section{Methods}

QoL was measured through the validated PedsQL ${ }^{\mathrm{Tm}}$ Generic Core Scale and the PedsQL ${ }^{\mathrm{mm}}$ Fatigue Scale [5-8].

The PedsQL ${ }^{\text {Tx }}$ Multidimensional Generic Core Scale has 23-items that encompass 4 sub-scales: 1) physical

Table 1 Sociodemographic and medical profiles of Children with $\mathrm{CAH}$

\begin{tabular}{|c|c|c|}
\hline Variables & N (\%) & Mean (SD) \\
\hline \multicolumn{3}{|l|}{ Sex } \\
\hline Male & $20(44)$ & \\
\hline Female & $25(45)$ & \\
\hline \multicolumn{3}{|l|}{ Race } \\
\hline Caucasian & $35(76)$ & \\
\hline Hispanic Latino & $3(7)$ & \\
\hline Mixed Race & $5(11)$ & \\
\hline Other & $2(4)$ & \\
\hline \multicolumn{3}{|l|}{ CAH Classifications } \\
\hline Salt-wasting & $25(56)$ & \\
\hline Simple-virilizing & $13(29)$ & \\
\hline Non-classic & $7(15)$ & \\
\hline Age at time of study (years) & & $8.22(4.53)$ \\
\hline \multicolumn{3}{|l|}{ Hydrocortisone Dose } \\
\hline Total Dose (mg/m²/day) & & $10.26(2.79)$ \\
\hline Morning Dose $\left(\mathrm{mg} / \mathrm{m}^{2} /\right.$ day $)$ & & $6.01(2.18)$ \\
\hline Bone Age Z-scores & & $2.01(2.79)$ \\
\hline Height Z-scores & & $0.62(1.36)$ \\
\hline
\end{tabular}

CAH congenital adrenal hyperplasia health (8 items), 2) emotional functioning (5 items), 3) social functioning (5 items), and 4) school functioning (5 items). Items are reverse scored and linearly transformed to a $0-100$ scale, with higher scores indicating better HRQL. Scales are comprised of parallel child self-report and parent proxy-report formats. The parent proxyreport forms are designed to assess the parents' perceptions of their child's HRQL. Healthy norms have been established in a cohort of 400 children and 717 parents in the United States [9].

The PedsQL ${ }^{\mathrm{m}}$ Multidimensional Fatigue Scale is an 18item self-report scale that includes three subscales: general (6 items), sleep/rest fatigue (6 items), and cognitive fatigue (6 items). Similar to the PedsQL ${ }^{\mathrm{mm}}$ Multidimensional Generic Core Scale, items on the Fatigue Scale are reverse scored and linearly transformed to a $0-100$ scale, with higher scores indicating less fatigue. Scales are comprised of parallel child self-report and parent proxy-report formats. Healthy U.S. norms have been established in a cohort of 42 children and 102 parents [7].

Overall control of $\mathrm{CAH}$ was measured with bone age Z-scores. In addition to monitoring growth and 17hydroxyprogesterone and androstenedione levels at every visit, bone age films were obtained every 6 months. Change in bone age in relation to chronological age is a valid predictor of overall adrenal androgen control in response to treatment with hydrocortisone [10]. For this study, the most recent bone age films were obtained within 1 year of the questionnaires and were read using the Greulich and Pyle method. The bone age Z-scores were then calculated using the bone age and the standard deviation for each child's sex and chronological age. The same was done for height $\mathrm{Z}$-scores.

\section{Statistical analysis}

SPSS Version 22 was used to perform the statistical analysis. The mean scores for the general pediatric population for each functional domain on the PedsQL ${ }^{\mathrm{mm}}$ Generic Core Scale [9] and the PedsQL ${ }^{\mathrm{Tn}}$ Fatigue Scale questionnaires [7] were compared to the mean scores of children with $\mathrm{CAH}$. A two-sample t-test was used to compare mean scores between children with $\mathrm{CAH}$ and published healthy norms and between parents of children with $\mathrm{CAH}$ and parents of published healthy norms [7, 9]. Differences in PedsQL ${ }^{\text {mix }}$ (Generic and Fatigue) scores between children with $\mathrm{CAH}$ and their parents were also evaluated using a $\mathrm{t}$-test. A one-way between groups analysis of variance was used to determine if PedsQL ${ }^{\mathrm{m}}$ (Generic and Fatigue) scores differed by gender and $\mathrm{CAH}$ subtype. Relationships between child and parent ratings of HRQL or Fatigue QoL and hydrocortisone doses, both morning dose $\left(\mathrm{mg} / \mathrm{m}^{2} /\right.$ day $)$ and total daily dose $\left(\mathrm{mg} / \mathrm{m}^{2} /\right.$ day $)$, were examined using Pearson's Correlation Coefficient. The correlations between bone age Z-scores and PedsQL ${ }^{\mathrm{mi}}$ (Generic and Fatigue) 
scores, and between height Z-scores and PedsQL ${ }^{\mathrm{mat}}$ (Generic and Fatigue) scores, were also measured using Pearson's Correlation Coefficient. A $p$-value of 0.05 was used as the significance level for each comparison and each correlation.

\section{Results}

Children with $\mathrm{CAH}$ did not report lower scores on the overall PedsQL ${ }^{\mathrm{Tm}}$ Generic Core or subscales compared to healthy child norms [Table 2] and even rated their physical health higher than healthy children $(95 \%$ CI $(2.10$, 10.14), $p=0.0$.

However, parents' reports of their children with $\mathrm{CAH}$ were significantly lower on the overall PedsQL ${ }^{\mathrm{mm}}$ Generic Core $(95 \%$ CI $(-7.37,-0.05), p=0.05)$, and on the emotional functioning (95\% CI $(-12.36,-1.12), p=0.02)$ and the school functioning subscales $(95 \%$ CI $(-12.75,-0.21), p=0.04)$ than parents' reports of healthy norms [Table 2]. Children with $\mathrm{CAH}$ and their parents did not differ significantly in how they rated the child's overall QoL on the PedsQL ${ }^{\mathrm{m}}$ Generic Core and subscales [Table 3].

Children with $\mathrm{CAH}$ did not report lower scores on the overall PedsQL ${ }^{\mathrm{Tx}}$ Fatigue total or subscales compared to healthy child norms [Table 2]. However, parents of children with $\mathrm{CAH}$ reported significantly lower scores on the overall PedsQL ${ }^{\mathrm{mi}}$ Fatigue total $(95 \%$ CI $(-12.24,-3.22)$, $p=0.001)$ and the general fatigue $(95 \% \mathrm{CI}(-12.34,-1.46)$, $p=0.01)$, sleep/rest fatigue (95\% CI $(-12.14,-2.38)$, $p=0.005)$, and cognitive fatigue subscales $(95 \% \mathrm{CI}$ $(-15.72,-2.52), p=0.008)$ than parents of healthy norms [Table 2]. Children with $\mathrm{CAH}$ and their parents did not differ significantly in how they rated the child's overall QoL on the PedsQL ${ }^{\mathrm{rm}}$ Fatigue total and subscales except on the sleep/rest fatigue subscale, where children reported poorer sleep/rest fatigue than their parents $(95 \% \mathrm{CI}$ $(-11.92,-1.52), p=0.01)$ [Table 3].
PedsQL ${ }^{\mathrm{mm}}$ Generic and Fatigue scores did not differ by sex, CAH subtype, morning or total hydrocortisone doses $\left(\mathrm{mg} / \mathrm{m}^{2} /\right.$ day), or height Z-scores. Child and parent PedsQL ${ }^{\text {tw }}$ Generic and Fatigue scores were examined for differences by sex, CAH subtype, morning or total hydrocortisone doses $\left(\mathrm{mg} / \mathrm{m}^{2} /\right.$ day $)$, and height Z-scores; no significant differences were found. However, among children with $\mathrm{CAH}$, there was a negative correlation between bone age Z-scores and child-reported scores on the following two subscales: emotional health $(p=0.01)$ from the PedsQL ${ }^{\mathrm{mm}}$ Generic Core and cognitive fatigue $(p=0.02)$ from the PedsQL ${ }^{\mathrm{mm}}$ Fatigue Scale [Fig. 1].

\section{Discussion}

As healthcare shifts to a more patient-centered approach, HRQL and measures of fatigue become more important measures of health outcomes [11, 12]. HRQL questionnaires are short, validated screening tools that are particularly useful when treating children with chronic conditions, such as $\mathrm{CAH}$, to understand how the disease and therapy impact physical, emotional, and social functioning [13]. There are only two previous studies that examined QoL in children with CAH using validated HRQL screening tools [3, 4]. However, these studies did not examine the relationship between QoL scores and hydrocortisone dosing or chronic androgen exposure, as measured by bone age Z-scores. There are no studies in children with $\mathrm{CAH}$ that have examined fatigue using a standardized multidimensional assessment.

In contrast to the two previous reports [3, 4], our pediatric participants with $\mathrm{CAH}$ did not report lower overall PedsQL ${ }^{\mathrm{m}}$ Generic scores than healthy norms. In fact, they scored significantly higher on the physical health subscale. What may account for the differences with other studies is that our children with $\mathrm{CAH}$ were only on hydrocortisone, which has been found to have

Table 2 Peds QoL Generic and Fatigue Scores: In relation to norms

\begin{tabular}{|c|c|c|c|c|c|c|}
\hline QoL Score, Mean & $\begin{array}{l}\text { Children with } \\
\text { CAH }\end{array}$ & $\begin{array}{l}\text { Healthy } \\
\text { Children }\end{array}$ & $\begin{array}{l}\text { Mean difference } \\
(95 \% \mathrm{Cl})\end{array}$ & $\begin{array}{l}\text { Parents, CAH } \\
\text { Children }\end{array}$ & $\begin{array}{l}\text { Parents, Healthy } \\
\text { Children }\end{array}$ & $\begin{array}{l}\text { Mean difference } \\
(95 \% \mathrm{Cl})\end{array}$ \\
\hline \multicolumn{7}{|c|}{ Generic QoL Scores (Overall and subscales) } \\
\hline Overall & $82.71(n=32)$ & $83.00(n=401)$ & $-0.29(-.25,5.67)$ & $83.90(n=43)$ & $87.61(n=717)$ & $-3.71(-7.37,-0.05)^{\mathrm{a}}$ \\
\hline Physical & $90.53(n=32)$ & $84.41(n=400)$ & $6.12(2.10,10.14)^{\mathrm{a}}$ & $89.10(n=44)$ & $89.32(n=717)$ & $-0.22(-3.52,3.08)$ \\
\hline Emotional & $80.16(n=32)$ & $80.86(n=400)$ & $-0.70(-6.96,5.55)$ & $75.90(n=44)$ & $82.64(n=717)$ & $-6.74(-12.36,-1.12)^{\mathrm{a}}$ \\
\hline Social & $85.16(n=32)$ & $87.42(n=399)$ & $-2.26(-10.11,5.58)$ & $90.60(n=43)$ & $91.56(n=716)$ & $-0.96(-4.57,2.65)$ \\
\hline School & $75.00(n=32)$ & $78.63(n=386)$ & $-3.63(-9.78,2.52)$ & $78.99(n=40)$ & $85.47(n=611)$ & $-6.48(-12.75,-0.21)^{\mathrm{a}}$ \\
\hline \multicolumn{7}{|c|}{ Fatigue Scores (Overall and subscales) } \\
\hline Overall & $79.08(n=32)$ & $80.49(n=52)$ & $-1.41(-7.85,5.02)$ & $81.90(n=42)$ & $89.63(n=102)$ & $-7.73(-12.24,-3.22)^{\mathrm{a}}$ \\
\hline General & $82.81(n=32)$ & $85.34(n=52)$ & $-2.53(-9.13,4.07)$ & $82.40(n=42)$ & $89.30(n=102)$ & $-6.90(-12.34,-1.46)^{a}$ \\
\hline Sleep/Rest & $74.48(n=32)$ & $75.00(n=52)$ & $-0.52(-8.30,7.25)$ & $81.60(n=42)$ & $88.86(n=102)$ & $-7.26(-12.14,-2.38)^{a}$ \\
\hline Cognitive & $79.97(n=31)$ & $81.14(n=52)$ & $-1.17(-10.71,8.37)$ & $81.60(n=42)$ & $90.72(n=102)$ & $-9.12(-15.72,-2.52)^{a}$ \\
\hline
\end{tabular}

andicates a significant finding at the 0.05 significance level

$C A H$ congenital adrenal hyperplasia, QoL quality of life 
Table 3 Peds QoL Generic and Fatigue Scores: Comparing the children with $\mathrm{CAH}$ to their parents

\begin{tabular}{|c|c|c|c|}
\hline QoL Score, Mean & $\begin{array}{l}\text { Children } \\
\text { with CAH }\end{array}$ & $\begin{array}{l}\text { Parents of } \\
\text { CAH Children }\end{array}$ & $\begin{array}{l}\text { Mean difference } \\
(95 \% \mathrm{Cl})\end{array}$ \\
\hline \multicolumn{4}{|c|}{ Generic QoL Scores (Overall and subscales) } \\
\hline Overall & $82.91(n=30)$ & $83.30(n=30)$ & $-0.39(-5.81,5.03)$ \\
\hline Physical & $90.42(n=31)$ & $89.11(n=31)$ & $1.31(-4.68,7.30)$ \\
\hline Emotional & $80.32(n=31)$ & $75.97(n=31)$ & $4.35(-1.36,10.07)$ \\
\hline Social & $85.50(n=30)$ & $90.33(n=30)$ & $-4.83(-13.53,3.86)$ \\
\hline School & $74.67(n=30)$ & $77.33(n=30)$ & $-2.67(-9.23,3.91)$ \\
\hline \multicolumn{4}{|c|}{ Fatigue Scores (Overall and subscales) } \\
\hline Overall & $79.77(n=30)$ & $82.36(n=30)$ & $-2.59(-6.99,1.81)$ \\
\hline General & $83.33(n=31)$ & $82.12(n=31)$ & $1.21(-3.50,5.92)$ \\
\hline Sleep/Rest & $75.80(n=31)$ & $82.52(n=31)$ & $-6.72(-11.92,-1.52)^{\mathrm{a}}$ \\
\hline Cognitive & $80.14(n=30)$ & $82.36(n=30)$ & $-2.22(-9.64,5.20)$ \\
\hline
\end{tabular}

andicates a significant finding at the 0.05 significance level

$C A H$ congenital adrenal hyperplasia, $Q L L$ quality of life

less of a negative impact on QoL in adults than other glucocorticoids [14]. In addition, the children with $\mathrm{CAH}$ in our study received circadian hydrocortisone administration, with the highest dose given in the early morning hours. Circadian hydrocortisone delivery has been shown to improve QoL in adults with adrenal insufficiency and $\mathrm{CAH}[15,16]$.

Similar to findings from the other two studies [3, 4], parents of children with $\mathrm{CAH}$ in our study reported a negative impact that the disease had on their children. Parents also reported significantly lower overall QoL, emotional health, and school functioning scores on the PedsQL ${ }^{\mathrm{TM}}$ Generic Core Scale compared to the parents of healthy norms.

Gilban, et al., a cross-sectional study of 25 participants with $\mathrm{CAH}$ (mean age 11.4 years), found that children with $\mathrm{CAH}$ reported lower overall QoL and lower physical and psychosocial QoL (encompassing social, emotional, and academic scores) [3]; however, only three of the participants were treated with hydrocortisone. The rest with prednisone or dexamethasone. This study found that bone age was on average 2.8 (2.2) years advanced when compared with chronological age but did not specifically examine how QoL varies by advanced bone age or bone age Z-scores, as our study did. Similar to our study, Gilban, et al., did not find any differences in QoL scores between sex and CAH subtypes, and parents of children with $\mathrm{CAH}$ reported lower physical and psychosocial scores for their children than parents of healthy norms.

Yau, et al., examined QoL in 33 children with $\mathrm{CAH}$ and compared these results to healthy norms and 14 children with hypothyroidism [4]. Children with $\mathrm{CAH}$ reported lower scores in overall QoL and in all of the subcategories: physical, emotional, social, and academic when compared with healthy norms. Children with $\mathrm{CAH}$ also reported lower school performance than children with hypothyroidism which was thought to be due to the number of missed days of school for illness and doctor appointments. Parents of children with $\mathrm{CAH}$ also reported lower scores for overall QoL and emotional functioning for their children than parents of healthy norms, but there was no significant difference found between scores of parents of children with $\mathrm{CAH}$ and parents of children with hypothyroidism. This study did not report which glucocorticoids the children with $\mathrm{CAH}$ were taking.

In our study, we also found no difference in PedsQL ${ }^{\mathrm{Tm}}$ Fatigue scores between children with $\mathrm{CAH}$ and healthy norms and no difference between children with $\mathrm{CAH}$ and their parents except in the sleep/rest PedsQL ${ }^{\text {тм}}$ Fatigue subscale, where children reported significantly lower scores. A possible explanation for similar fatigue scores between children with $\mathrm{CAH}$ and healthy norms could be that the baseline expectation of "feeling normal" may be lower in children with $\mathrm{CAH}$, as it reflects the way they have felt since birth. Children with late onset acquired adrenal insufficiency, for example, can compare a perceived change in QoL before and after disease onset, whereas children with $\mathrm{CAH}$ have no other point of reference [17]. This adaptation by children with $\mathrm{CAH}$ to their impairment is a phenomenon known to occur in other chronic congenital diseases [18] and has been noted in adults with $\mathrm{CAH}$, who reported less fatigue compared to adults with other forms of adrenal insufficiency diagnosed later in life [19]. It is also possible the higher adrenal androgen levels in children with $\mathrm{CAH}$ compared to controls may ameliorate the fatigue associated with hypocortisolemia. The lower sleep/rest fatigue subscale score reported by children with $\mathrm{CAH}$ when compared to their parents may be attributed to the evening hydrocortisone dose. Based on diurnal cortisol secretion, levels between $6 \mathrm{pm}$ and 12 am are at their nadir in healthy children [20], which is during the time frame that children with $\mathrm{CAH}$ are typically getting their evening dose $(8-10 \mathrm{pm})$. This results in a cortisol peak during a time that cortisol should be at its lowest based on the physiologic cortisol circadian rhythm. Children with higher cortisol levels before bedtime have been shown to have shorter duration of sleep and lower sleep efficiency [21, 22].

Parents of children with $\mathrm{CAH}$ reported significantly lower total and all subscale scores on the PedsQL ${ }^{\text {тм }}$ Fatigue Scale than parents of healthy norms. This is not surprising as parents of children with chronic diseases, in general, have been found to over-report poorer QoL in their children, and they may be reporting their own feelings of having a child with a long term medical condition requiring therapy [12]. 


\section{a Correlation between Bone Age and Emotional Health}

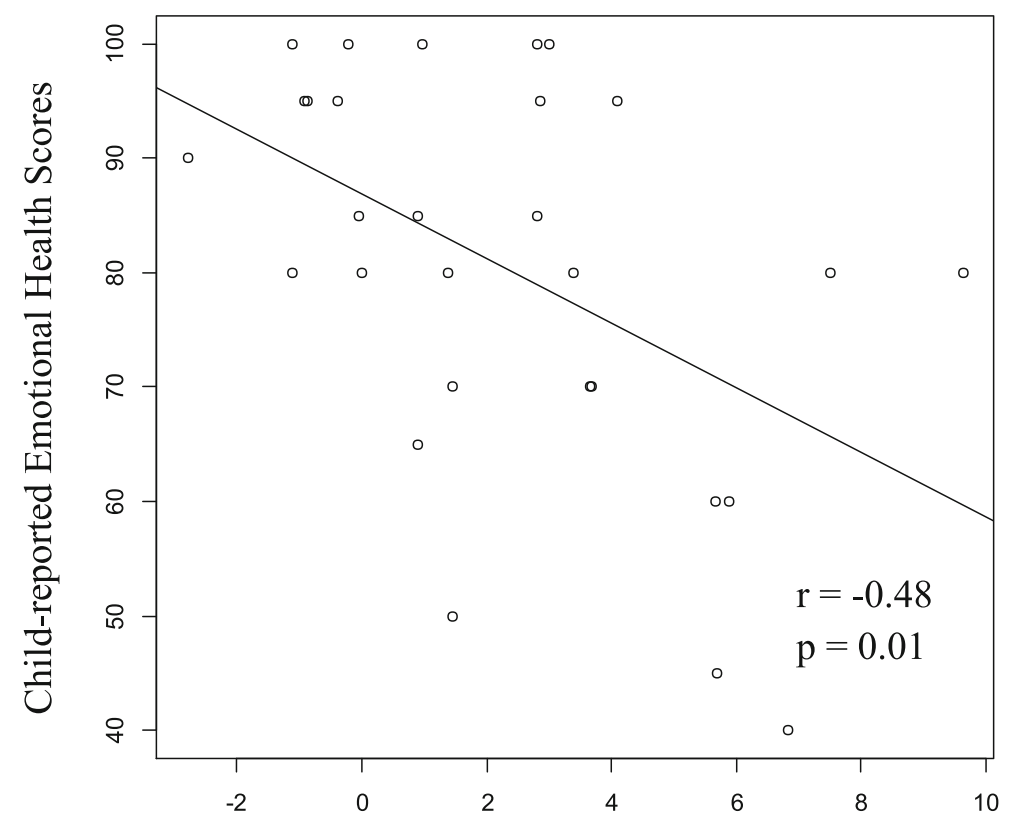

Bone Age Z-score

\section{b Correlation between Bone Age and Cognitive Fatigue}

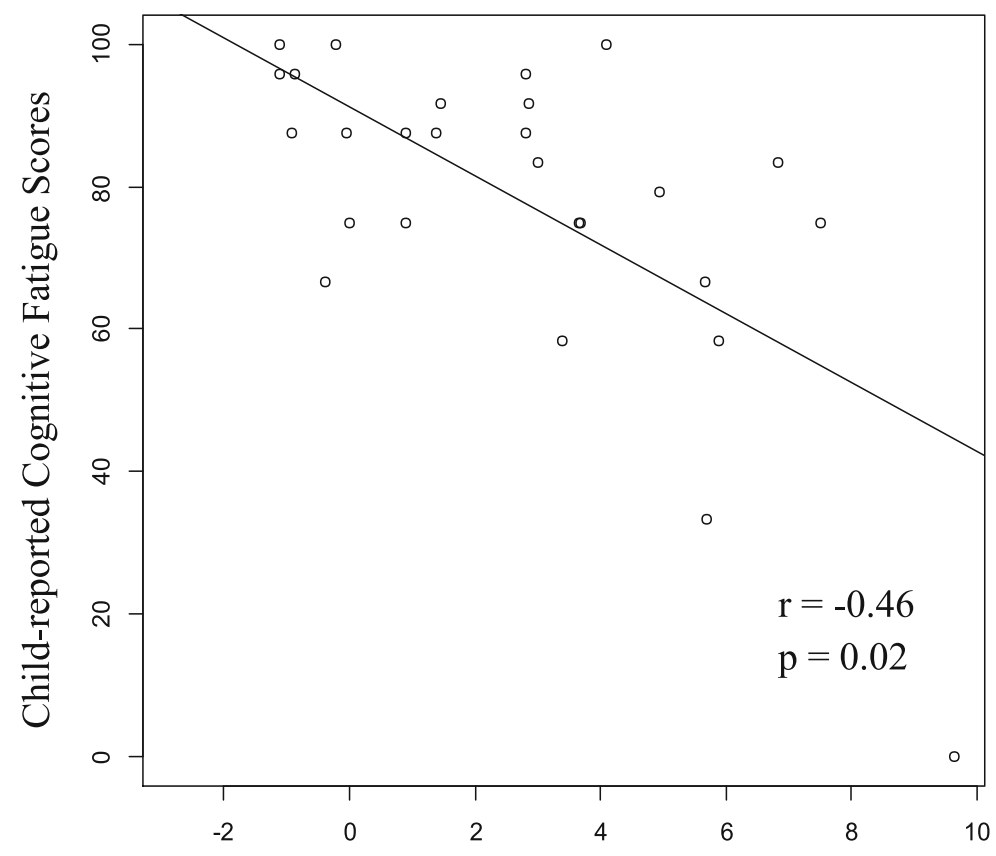

Bone Age Z-score

Fig. 1 a displays the correlation between bone age Z-scores and child-reported emotional health, and $\mathbf{b}$ displays the correlation between bone age Z-scores and child-reported cognitive fatigue scores in children with CAH 
One Dutch study using non-validated, self-designed QoL questionnaires showed that parents of children with $\mathrm{CAH}$ tended to report sleepiness and decreased energy in their children, similar to findings in our study [23]. The majority of children in this study were taking hydrocortisone.

While we found no correlation between daily hydrocortisone dose (morning or total), sex, disease subtype, or height Z-scores and PedsQL ${ }^{\mathrm{Tw}}$ Generic and Fatigue scores, we did find that higher bone age Z-scores, indicating more advanced bone age and increased androgen exposure, correlated with lower scores on the emotional health and cognitive fatigue subscales among children with $\mathrm{CAH}$. Although one would expect that lower hydrocortisone doses would be associated with increased androgen exposure and lower scores, the lack of correlation between hydrocortisone dose and Peds $\mathrm{QL}^{\mathrm{ma}}$ Generic and Fatigue scores suggest that inter-individual glucocorticoid sensitivity and cortisol kinetics should be considered when determining the best treatment regimen for these patients.

One limitation of this study is our use of standardized norms. Although standardized, environmental factors may play a role in QoL, so the results may not exactly reflect those of healthy controls living in Minnesota.

\section{Conclusion}

Our study found that although children may not see the effect that their chronic disease has on their lives, their parents do see the impact of CAH. PedsQL ${ }^{\mathrm{m}}$ Generic and Fatigue scores did not differ by sex, CAH subtype, morning or total hydrocortisone doses $(\mathrm{mg} / \mathrm{m} 2 /$ day), or height Z-scores. However, negative associations between bone age Z-scores and emotional health or cognitive fatigue suggest an impact from chronic hypocortisolemia and hyperandrogenemia. More studies to specifically look at circadian versus non-circadian administration of hydrocortisone, and androgen and hydrocortisone exposure over the course of the day through pharmacokinetics and pharmacodynamics studies and its effects on HRQL are needed.

\section{Abbreviations \\ $\mathrm{CAH}$ : Congenital adrenal hyperplasia; HRQL: Health-related quality of life; QoL: Quality of life}

\section{Acknowledgements}

Not applicable.

\section{Funding}

Not applicable.

\section{Availability of data and materials}

The datasets used and/or analyzed during the current study are available from the corresponding author on reasonable request.

\section{Authors' contributions}

AH contributed to the concept and design of the study and the interpretation of data, drafted the initial manuscript, approved the final manuscript, and agreed to ensure that questions related to the accuracy or integrity of any part of the work are appropriately investigated and resolved. $\mathrm{MH}$ performed the statistical analysis, drafted the initial statistical methods section, approved the final manuscript, and agreed to ensure that questions related to the accuracy or integrity of any part of the work are appropriately investigated and resolved. MG contributed to the acquisition of data and the revision and review of the article, approved the final manuscript, and agreed to ensure that questions related to the accuracy or integrity of any part of the work are appropriately investigated and resolved. NV contributed to the acquisition of data and the revision and review of the article, approved the final manuscript, and agreed to ensure that questions related to the accuracy or integrity of any part of the work are appropriately investigated and resolved. TT contributed to the analysis and critical review of the manuscript, approved the final manuscript, and agreed to ensure that questions related to the accuracy or integrity of any part of the work are appropriately investigated and resolved. JT contributed to the acquisition of data and the revision and review of the article, approved the final manuscript, and agreed to ensure that questions related to the accuracy or integrity of any part of the work are appropriately investigated and resolved. KS conceptualized and designed the study, contributed to the interpretation of data, critically revised the manuscript, approved the final manuscript, and agreed to ensure that questions related to the accuracy or integrity of any part of the work are appropriately investigated and resolved.

\section{Ethics approval and consent to participate}

The University of Minnesota Institutional Review Board approved the study, and informed consents from all participants and assents for children older than 7 years were obtained.

\section{Consent for publication}

Not applicable.

\section{Competing interests}

The authors declare that they have no competing interests.

\section{Publisher's Note}

Springer Nature remains neutral with regard to jurisdictional claims in published maps and institutional affiliations.

\section{Author details}

'University of Minnesota Masonic Children's Hospital, 2450 Riverside Ave. East Bldg, Rm MB671, Minneapolis, MN 55454, USA. ${ }^{2}$ University of Minnesota School of Nursing, Minneapolis, MN, USA. ${ }^{3}$ University of Minnesota College of Pharmacy, Minneapolis, MN, USA. ${ }^{4}$ Minnesota Department of Health, St. Paul, MN, USA.

Received: 10 May 2017 Accepted: 27 September 2017

Published online: 06 October 2017

\section{References}

1. Speiser PW, Azziz R, Baskin LS, Ghizzoni L, Hensle TW, Merke DP, MeyerBahlburg HF, Miller WL, Montori VM, Oberfield SE, et al. Congenital adrenal hyperplasia due to steroid 21-hydroxylase deficiency: an Endocrine Society clinical practice guideline. J Clin Endocrinol Metab. 2010;95:4133-60.

2. Sarafoglou K, Zimmerman CL, Gonzalez-Bolanos MT, Willis BA, Brundage R. Interrelationships among cortisol, 17-hydroxyprogesterone, and androstenendione exposures in the management of children with congenital adrenal hyperplasia. J Investig Med. 2015;63:35-41.

3. Gilban DL, Alves Junior PA, Beserra IC. Health related quality of life of children and adolescents with congenital adrenal hyperplasia in Brazil. Health Qual Life Outcomes. 2014;12:107.

4. Yau M, Vogiatzi M, Lewkowitz-Shpuntoff A, Nimkarn S, Lin-Su K. HealthRelated Quality of Life in Children with Congenital Adrenal Hyperplasia. Horm Res Paediatr. 2015:84:165-71.

5. Varni JW, Burwinkle TM, Seid M. The PedsQL as a pediatric patient-reported outcome: reliability and validity of the PedsQL Measurement Model in 25,000 children. Expert Rev Pharmacoecon Outcomes Res. 2005;5:705-19. 
6. Varni JW, Burwinkle TM, Seid M, Skarr D. The PedsQL 4.0 as a pediatric population health measure: feasibility, reliability, and validity. Ambul Pediatr. 2003;3:329-41.

7. Varni JW, Burwinkle TM, Katz ER, Meeske K, Dickinson P. The PedsQL in pediatric cancer: reliability and validity of the Pediatric Quality of Life Inventory Generic Core Scales, Multidimensional Fatigue Scale, and Cancer Module. Cancer. 2002;94:2090-106.

8. Varni JW, Limbers CA, Bryant WP, Wilson DP. Assessment of fatigue in pediatric patients with short stature utilizing the PedsQL ${ }^{\text {TM }}$ multidimensional fatigue scale. Chil Health Care. 2012;41:162-81.

9. Varni JW, Seid M, Kurtin PS. PedsQL 4.0: reliability and validity of the Pediatric Quality of Life Inventory version 4.0 generic core scales in healthy and patient populations. Med Care. 2001;39:800-12.

10. Kwon JH, Lee HA, Kim YJ, Lee H, Park EA, Cho SJ, Gwak HS, Ha E, Park H, Kim HS. Effects of Adrenal Androgen Levels on Bone Age Advancement in Prepubertal Children: Using the Ewha Birth and Growth Cohort Study. J Korean Med Sci. 2017;32:968-73.

11. Eiser C, Morse R. A review of measures of quality of life for children with chronic illness. Arch Dis Child. 2001;84:205-11.

12. Ingerski LM, Modi AC, Hood KK, Pai AL, Zeller M, Piazza-Waggoner C, Driscoll KA, Rothenberg ME, Franciosi J, Hommel KA. Health-related quality of life across pediatric chronic conditions. J Pediatr. 2010;156:639-44.

13. Cantrell MA, Kelly MM. Health-related quality of life for chronically ill children. MCN Am J Matern Child Nurs. 2015:40:24-31.

14. Han TS, Krone N, Willis DS, Conway GS, Hahner S, Rees DA, Stimson RH, Walker BR, Arlt W, Ross RJ. United Kingdom Congenital adrenal Hyperplasia Adult Study E: Quality of life in adults with congenital adrenal hyperplasia relates to glucocorticoid treatment, adiposity and insulin resistance: United Kingdom Congenital adrenal Hyperplasia Adult Study Executive (CaHASE). Eur J Endocrinol. 2013;168:887-93.

15. Nella AA, Mallappa A, Perritt AF, Gounden V, Kumar P, Sinaii N, Daley LA Ling A, Liu CY, Soldin SJ, Merke DP. A Phase 2 Study of Continuous Subcutaneous Hydrocortisone Infusion in Adults With Congenital Adrenal Hyperplasia. J Clin Endocrinol Metab. 2016;101:4690-8.

16. Johannsson G, Nilsson AG, Bergthorsdottir R, Burman P, Dahlqvist P, Ekman $\mathrm{B}$, Engstrom BE, Olsson T, Ragnarsson O, Ryberg M, et al. Improved cortisol exposure-time profile and outcome in patients with adrenal insufficiency: a prospective randomized trial of a novel hydrocortisone dual-release formulation. J Clin Endocrinol Metab. 2012;97:473-81.

17. Reisch N, Hahner S, Bleicken B, Flade L, Pedrosa Gil F, Loeffler M, Ventz M, Hinz A, Beuschlein F, Allolio B, et al. Quality of life is less impaired in adults with congenital adrenal hyperplasia because of 21-hydroxylase deficiency than in patients with primary adrenal insufficiency. Clin Endocrinol. 2011;74:166-73.

18. Tanaka T, Tai S, Morisaki Y, Tachibana K, Kambayashi Y, Chihara K, Seino Y, Fujieda K. Evaluation of Quality of Life in Children with GH Deficiency and Idiopathic Short Stature Using the Child Behavior Checklist. Clin Pediatr Endocrinol. 2009;18:15-22.

19. Forss M, Batcheller G, Skrtic S, Johannsson G. Current practice of glucocorticoid replacement therapy and patient-perceived health outcomes in adrenal insufficiency - a worldwide patient survey. BMC Endocr Disord. 2012;12:8.

20. Peters CJ, Hill N, Dattani MT, Charmandari E, Matthews DR, Hindmarsh PC Deconvolution analysis of 24-h serum cortisol profiles informs the amount and distribution of hydrocortisone replacement therapy. Clin Endocrinol. 2013;78:347-51.

21. Raikkonen K, Matthews KA, Pesonen AK, Pyhala R, Paavonen EJ, Feldt K, Jones A, Phillips DI, SeckI JR, Heinonen K, et al. Poor sleep and altered hypothalamic-pituitary-adrenocortical and sympatho-adrenal-medullary system activity in children. J Clin Endocrinol Metab. 2010;95:2254-61.

22. Kumari M, Badrick E, Ferrie J, Perski A, Marmot M, Chandola T. Self-reported sleep duration and sleep disturbance are independently associated with cortisol secretion in the Whitehall II study. J Clin Endocrinol Metab. 2009:94:4801-9.

23. Sanches SA, Wiegers TA, Otten BJ. Claahsen-van der Grinten HL: Physical, social and societal functioning of children with congenital adrenal hyperplasia (CAH) and their parents, in a Dutch population. Int J Pediatr Endocrinol. 2012;2012:2.

\section{Submit your next manuscript to BioMed Central and we will help you at every step:}

- We accept pre-submission inquiries

- Our selector tool helps you to find the most relevant journal

- We provide round the clock customer support

- Convenient online submission

- Thorough peer review

- Inclusion in PubMed and all major indexing services

- Maximum visibility for your research

Submit your manuscript at www.biomedcentral.com/submit

) Biomed Central 